\title{
DEEP NECK SPACE INFECTION - DIAGNOSTIC AND THERAPEUTIC CHALLENGES: TWO CASE REPORTS
}

\section{Anca R. MOSOIU ${ }^{1 凶}$, Oana M. MUSTEATA ${ }^{1}$, Raluca GRIGORE ${ }^{1,2}$, Serban V.G. BERTESTEANU ${ }^{1,2}$, Alina L.A. OANCEA ${ }^{1,2}$}

${ }^{1}$ ENT Department, Clinical Hospital Coltea, Bucharest, Romania

2 University of Medicine and Pharmacy „Carol Davila“, Bucharest, Romania

Received 05 Oct 2019, Accepted 12 Nov 2019

https://doi.org/10.31688/ABMU.2019.54.4.24

\section{Abstract}

Introduction. The infections of the deep neck spaces, are often a clinical challenge, being a medico-surgical emergency with a bad prognosis and lethal potential in the absence of early diagnosis and well applied treatment.

Case report 1. The first case presented is a woman, 72-year-old, known with anaemia due to myelodysplastic syndrome, admitted in the haematology department. The symptoms were dysphagia with odynophagia and right submandibular tumefaction, on an afebrile background.

In this case the infection started with the peritonsillar abscess which then developed into a parapharyngeal abscess.

The main medical difficulties appeared after the surgery, the general condition of the patient worsening despite the favourable evolution of the surgical wound. A total recovery, including deglutition, was possible two months after discharge.

Case report 2. The second patient is a young female, aged 26, with a good social and material status, without associated comorbidities.

The triggering factor is the extraction of the 3.7 molar prior to the appearance of the symptoms.

\section{Résumé}

Infections profondes de l'espace cervical - défis diagnostiques et thérapeutiques

Introduction. Les infections des espaces plus profonds du cou sont souvent un défi clinique, en tant qu'urgences médico-chirurgicales à un mauvais pronostic et un potentiel mortel dans l'absence d'un diagnostic précoce et bien appliqué.

Rapport du cas 1. Le premier cas présenté est celui d'une femme de 72 ans atteinte d'anémie due au syndrome myélodysplasique, admise au service d'hématologie. Les symptômes étaient une dysphagie avec odynophagie et une tuméfaction sous-maxillaire droite, sur un fond apyrétique.

Dans ce cas, l'infection a commencé par un abcès péri-amygdalien qui s'est ensuite développé en un abcès para-pharyngé.

Les principales difficultés médicales sont apparues après la chirurgie, l'état général du patient s'aggravant malgré l'évolution favorable de la plaie chirurgicale. Une récupération totale, y compris la déglutition, était possible deux mois après avoir quitte l'hôpital.

Rapport du cas 2. La deuxième patiente est une jeune femme de 26 ans avec un bon statut social et matériel, sans comorbidités associées. 
The condition of the patient was critical during the first seven days after surgery due to the severity of the cervical and mediastinal lesions.

\section{Conclusions}

The management of deep neck infections is a diagnostic and therapeutic challenge, and must be based on the multidisciplinary aid. The prevalence of deep neck infections is decreasing, due to antibiotics, but still remains an ENT emergency.

Keywords: cervical suppurations, neck fascia layers, parapharyngeal collection, exploratory cervicotomy, neck CT scan.

\section{INTRODUCTION}

The suppurating processes at the head and neck level are a medical and surgical emergency. The natural evolution of the disease is severe, life-threatening and potentially lethal, in the absence of early diagnosis and of correctly applied treatment. ${ }^{1}$ The difficulty in detecting and in treating such pathology arises from the local complex anatomy of these regions. The study of the cervical fascia presents major difficulties, including disputes related to classification and terminology among various authors. ${ }^{2}$ The number of cervical fascia is hard to systemize, as the main criterion should be the clinical one, explaining the propagation of the collection and allowing the operator to establish the surgical techniques.

The most common classification uses five fascia layers. $^{2}$

1. The subcutaneous fascia - encloses the deep surface of the adipose layer and forms the sheath for the platysma muscle.

2. The superficial lamina of the cervical fascia - inferior is fixed to the anterior side of the clavicle and of the sternum, superior to the inferior side of the mandible. It forms the sheath for the sternocleidomastoid muscle, trapezius muscle, submandibular gland. It also forms the sheath of the jugular carotid groove.

3. The deep lamina of the cervical fascia - it is incomplete, has the shape of a trapezius and extends from the hyoid bone up to the posterior side of the sternum and of the clavicle. It forms the aponeurotic sheath for the sternohyoid m., sternothyroid muscle, thyrohyoid muscle, omohyoid muscle.

4. The endocervical fascia - presents a parietal and a visceral lamina. The parietal lamina adheres to the sheath of the pre tracheal muscles group. The
Le facteur déclencheur est l'extraction de la molaire 3,7 avant l'apparition de symptômes.

L'état du patient était critique au cours des sept premiers jours suivant la chirurgie en raison de la gravité des lésions cervicales et médiastinales.

\section{Conclusions}

La gestion de ce type d'infections est une vraie provocation pour le diagnostic et le traitement doit être fondée sur un support multidisciplinaire. La prévalence de cette pathologie est en décroissance grâce à l'utilisation des antibiotiques, mais elle reste encore une réelle urgence en ORL.

Mots-clés: infections du cou, fasciae du cou, collection para-pharyngée, cervicotomie exploratrice, scanner du cou.

visceral lamina separates the parapharyngeal space into the parapharyngeal space proper (anterior and posterior) and retropharyngeal. The perivisceral aponeurotic lamina is fixed cranially to the bony protrusions at the base of the skull, and it caudally continues with the mediastinum layers. In the peri pharyngeal space, inside the visceral groove, there is the pharynx and outside the perivisceral aponeurotic lamina remain the stylohyoid and digastric muscles. Dorsally, the visceral groove is separate by the aponeurotic laminas of the ascending pharyngeal arteries into two retropharyngeal spaces symmetrically against the median line and located dorsally against the posterior wall of the pharynx. The perivisceral lamina with carotidal starting point separates the anterolateral cervical region into two regions: the visceral groove and cervical spaces. In its turn, the visceral lamina is separate by the aponeurotic lamina of the ascending pharyngeal artery into retropharyngeal and lateral pharyngeal spaces.

The spaces inside the visceral groove host the peri pharyngeal phlegmons, while the cervical spaces host the adenophlegmons with multiple starting points: rinosinusal, buccopharyngeal and laryngeal.

In the retropharyngeal groove, before the axis body, there are two lymph nodes, one each side of the median line, nodes which have been described by Gillette, and which become atrophied after the age of 3-4. The retropharyngeal space is bordered laterally by the Charpy sagittal laminas, which separate it from the maxilla pharyngeal space, while at the bottom they communicate with the posterior mediastinum. The nodes receive the nose cavity, nasopharynx, Luschka's joints, Eustachian tube, 
middle ear and dorsal face of the palatine bone lymph.

5. The prevertebral fascia - located on the prevertebral muscles.

Clinically, the cervical suppurations are classified as follows ${ }^{3}$ :

1. Peritonsillar phlegmon - suppuration of the lax cellular tissue between the palatine tonsillar capsule and the muscular wall of the pharynx

2. Retro/lateral pharyngeal adenophlegmons - suppuration located in the nodes at the level of these anatomic spaces

3. Lateral cervical cellular phlegmon (perivisceral phlegmon) - is a collection located between the pharyngeal wall and the vascular nervous package of the neck.

4. Diffuse phlegmon pharynx (Senator' disease) - diffuse gangrene of the pharyngeal wall

5. Phlegmonous lingual tonsillitis

6. Septic phlegmon of the floor of the mouth (Ludwigh's angina) - phlegmonous infiltration of the floor of the mouth

7. Epiglottic abscess - abscessed, isolated inflammation of the epiglottis

The etiopathological causes of the suppurations are multiple: infected chronic tonsillitis, dental infections, pharyngeal trauma, infectious contagious diseases, lesions of the pharyngeal mucus during endoscopic examinations, post-tonsillectomy. ${ }^{4,5}$

The most frequent pathogenic agents involved are: Streptococcus, Staphylococcus, Klebsiella, Pseudomonas aeruginosa, as well as the aerobic and anaerobic polymicrobial flora. ${ }^{6}$

The factors favourable for such developments are mainly the associations of comorbidities: diabetes, chronic renal insufficiency, liver failure, HIV, autoimmune diseases, radio/chemotherapy antecedents, chronic alcoholism, consumption of injectable drugs. There are studies demonstrating that the presence of the diabetes increases the risk of complications, e.g. mediastinitis, by about 5 times.?

The complications associated to cervical suppurations may be: acute obstruction of upper respiratory tract, mediastinitis, internal jugular vein thrombosis, carotid artery rupture, necrotizing fasciitis, pneumonia, sepsis. ${ }^{8,9}$

\section{Case Report 1}

The first patient is a female, 72-year-old, known with myelodysplastic syndrome, admitted in the haematology department for secondary anaemia, presents on the third day after admission dysphagia with odynophagia and right submandibular tumefaction, on an afebrile background, with a generally good condition.

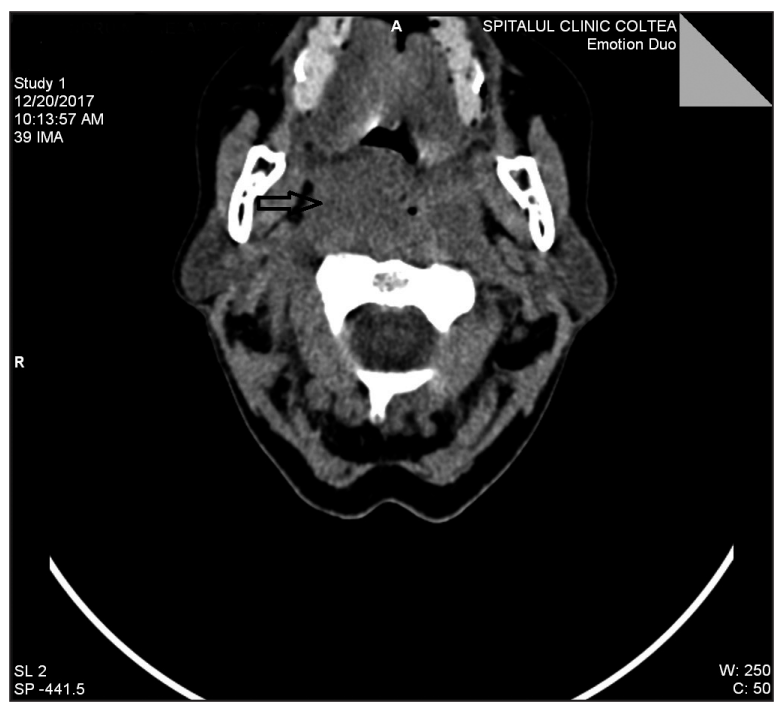

Fig. 1. Neck CT scan examination (without contrast substance). Space replacing process occupying the right parapharyngeal and retropharyngeal space at the level of the oropharynx, caudally extended up to the level of the pyriform sinus, and cranially up to the level of the cavum, with loose contours and non-homogenous structure by the presence of areas with fluid and parafluid densities inside, with mass effect over the pharyngeal lumen.

The ENT clinical examination revealed the swelling of the right hemi-palate and of the posterior tonsillar pillar on the right side, swelling of the lateral wall of the right pyriform sinus, salivary stasis at the level of the right pyriform sinus, normal laryngeal ring, normal glottal space. At right submandibular angle level, a tumefaction of about $2 / 3 \mathrm{~cm}$ has been identified, sensitive to touching, of moderate consistency, with superjacent teguments with normal aspect.

The puncture aspiration at the level of the right hemi-palate, at the maximum swelling point, revealed purulent secretions, being completed with large incision and drainage at this level. The secretion collected through puncture aspiration is sent for bacteriological examination with antibiogram. By the time the bacteriologic result is given, empirical intravenous antibiotic therapy has been performed, with a large spectrum - ceftriaxone $4 \mathrm{~g} /$ day and metronidazole $2 \mathrm{~g} /$ day.

Further to the CT scan examination (Fig.1) and to the local unfavourable evolution (swelling of the right lateral wall of the pyriform sinus and exacerbated salivary stasis at this level), a lateral cervical incision is made 75 hours after diagnosis, under general anaesthesia, with the drainage of the parapharyngeal collection, tracheotomy, placing of a nasogastric feeding tube.

The result of the bacteriological investigation was multiple sensitive Staphylococcus aureus (Table 1). 
Table 1. Evolution of the main biological constants

\begin{tabular}{|c|c|}
\hline Admission & 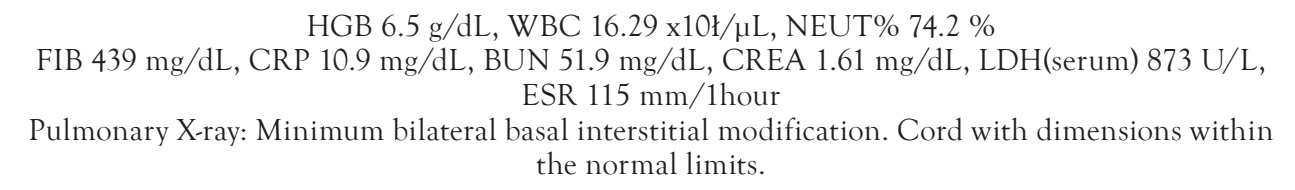 \\
\hline Pre-surgery & 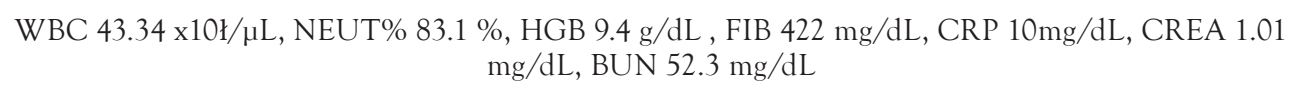 \\
\hline Post-surgery & 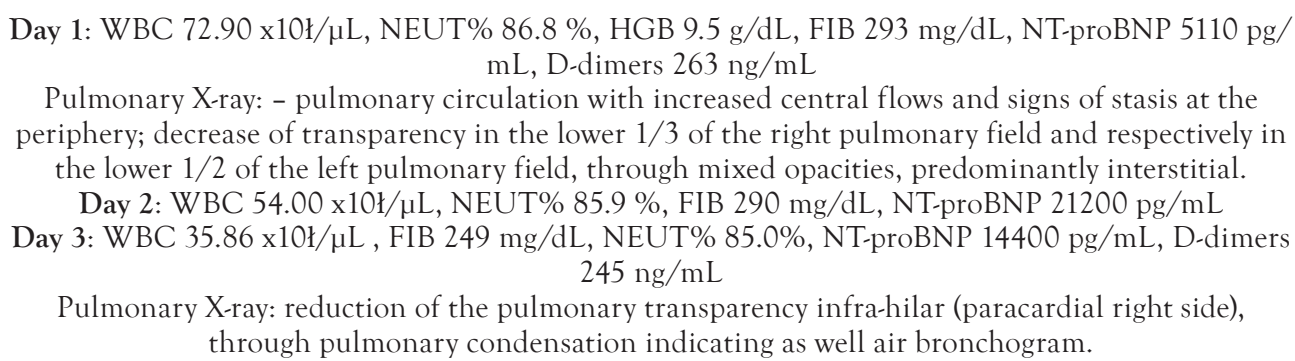 \\
\hline
\end{tabular}

Legend: $\mathrm{HGB}=$ hemoglobin, $\mathrm{WBC}=$ white blood cells, NEUT $=$ neutrophils, FIB $=$ fibrinogen, $\mathrm{CRP}=\mathrm{C}$-reactive protein, $\mathrm{CREA}=$ creatinine, $\mathrm{LDH}=$ lactic acid dehydrogenase, $\mathrm{ESR}=$ erythrocyte sedimentation rate, NT-proBNP $=\mathrm{N}$-terminal proB-type natriuretic peptide

24 hours after surgery, the patient developed leukemoid hyperleukocytosis $(72.90 \times 101 / \mu \mathrm{L})$ and her general condition worsened from cardio-respiratory point of view. The patient developed acute paroxysmal fibrillation and respiratory decompensation, requiring mechanical ventilation support for four days.

From surgical point of view, the lateral cervical wound was cleansed with abundant oxygenated water and betadine under general anaesthesia with endotracheal intubation. Seven days later, the lateral cervical wound was sutured per secundam.

In order to fight the pneumonic inflammatory process, developed 72 hours after surgery, treatment with antibiotic such as tienam, linezolid, colistin and ecalta was applied.

Two weeks after surgery, after the diminution of the tracheobronchial secretions and normalization of the image in the pulmonary $\mathrm{x}$-ray, the tracheal cannula was removed.

The patient was discharged after 20 days of hospitalization, with a nasogastric feeding tube until the deglutition became normal.

The particularities of the case are:

- The infection started with the peritonsillar abscess which then developed into a parapharyngeal abscess

- The developing factors are the immunosuppression induced by the underlying disease, i.e. the myelodysplasic syndrome and the age of the patient.

- The discrepancy between the symptomatology and the seriousness of the lesion. The clinical picture was not noisy, the dysphagia and the odynophagia being moderate, the submandibular angle adenitis being sensitive to touching, and the fever and trismus absent.

- The CT scan investigation of the cervical region was made without contrast substance due to the iodine allergy. This made it difficult to detect a reliable differentiation between cellulitis and abscess.

- During the surgery, it was confirmed that the starting point, i.e. the maximum abscess, had developed at peritonsillar level. A communication gap at the level of the hypopharynx was detected and the parapharyngeal collection was drained. The golden rule in case of such suppurations is for the surgical wound to be left open. The dressing shall be made through wrapping the wound with betadine impregnated tents, and the wound shall be cleansed daily, using antiseptic substances abundantly. Due to the existence of the gap at the level of the hypopharynx, tracheotomy was applied, this preventing the aspiration syndrome.

- The main medical difficulties appeared after the surgery, the general condition of the patient worsening despite the favourable evolution of the surgical wound. The patient developed cardio-respiratory decompensation, presenting acute paroxysmal fibrillation, pulmonary condensation points and a major biological imbalance (Table 1) The first 72 hours after surgery were critical, the patient requiring mechanical ventilation support. Wide spectrum antibiotics therapy was applied (tienam, linezolid, colistin and ecalta), the patient was assessed by echocardiography, surveyed through cardiac monitoring, reassessed radiologically through repeated pulmonary X-rays and thoracic CT scan, 
reassessed haematologically and monitored in the intensive care unit for 10 days.

- The evolution of the lateral cervical wound has not been problematic, being sutured per secundam seven days, and the tracheal cannula being removed fourteen days after the drainage of the purulent collection.

- After 10 hospitalization days within the intensive care unit, although having benefited from daily kineto-therapeutic care, the patient developed muscular hypotonia/atrophy, without being able to move alone. The full functional recovery was only possible after three months of kineto-therapy.

- Another issue was the recovery of the deglutition. The patient was discharged after 20 days preserving the nasogastric feeding tube, as she has developed dysphagia, mainly for liquids. The normal recovery of the deglutition was possible two months after discharge.

- Without a multi-disciplinary medical care/supervision - ENT, Intensive Care, cardiology, infectious diseases, radiology, kineto-therapy - the full curing and recovery in this complex case would not have been possible.

\section{Case Report 2}

The second patient is a young female, 26-year-old, who comes to the ENT emergency room for odynophagia, dysphagia, trismus and fever lasting for 4 days. The patient had an extraction of 3.7 molar 7 days before.

The ENT clinical examination revealed trismus, left hemi-palate, swelling of the lateral wall of the left pyriform sinus, salivary stasis at this level, normal laryngeal ring. The palpatory exam of the cervical region did not reveal lateral cervical sensitivity or tumefaction.

A puncture was applied at the level of the lateral wall of the left pyriform sinus, with aspiration of purulent secretion, which was then sent to bacteriologic examination and antibiogram.

The incision-drainage of the collection and the application of the nasogastric feeding tube were made under local anaesthesia.

In the next 72 hours, under wide spectrum antibiotics treatment - ceftriaxone $4 \mathrm{~g} /$ day and metronidazole $2 \mathrm{~g} /$ day, the evolution was favourable. Symptomatically, the patient remained a febrile, the dysphagia improved, the trismus disappeared and the local clinical examination revealed the reduction of the tumefaction at the level of the lateral wall of the left pyriform wall and the absence of purulent secretions.

On the fourth day after admission, the patient accused spontaneous left lateral cervical pain, intensified during deglutition, and the local clinical

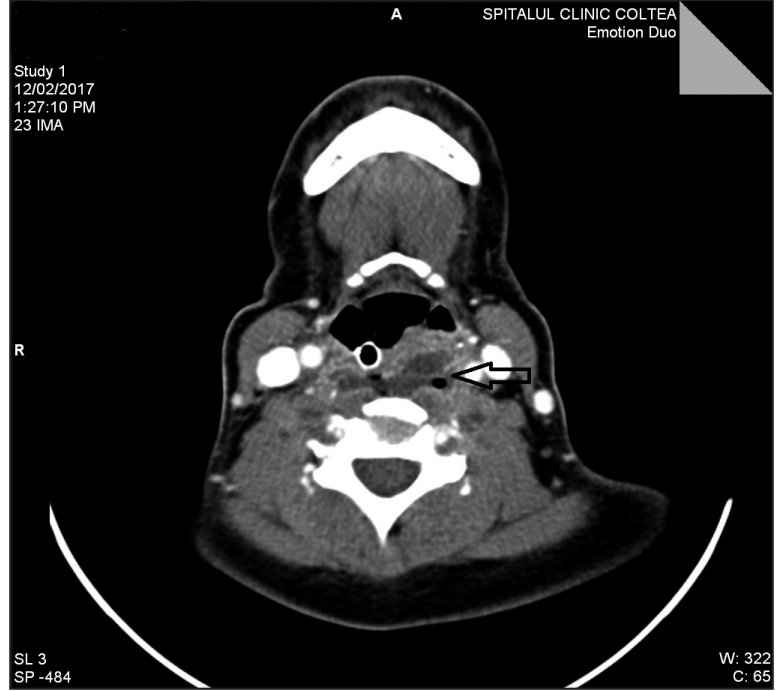

Fig. 2. Neck CT scan examination (with contrast substance). Accumulation of fluids with mixed densities, located in the left posterior lateral parapharyngeal space at the level of the oro - and laryngopharynx, leading to the narrowing of the lumen. It presents its own, iodophilic wall, it extends caudally posterior lateral left against the larynx and lateral left against the oesophagus. The collection exceeds the prevertebral fascia, comes in direct contact with the vertebral bodies, which are intact.

examination revealed purulent secretions at the level of the left pyriform sinus.

Further to the imaging investigations (Fig. 2), under general anaesthesia, an exploratory cervicotomy was carried out through large lateral cervical bilateral incisions, with the drainage of the para-and retropharyngeal purulent collection, and respectively from the level of the posterior superior mediastinum, followed by tracheotomy and drainage of the mediastinum through aspiration. After surgery, antibiotics treatment with meronem and vancomycin was applied, and the wound was cleaned for 10 days under general anaesthesia. The patient was discharged after 27 days of hospitalization in a general good condition, without nasogastric feeding tube.

The particularities of this case are:

- Young patient, 26 yo, with a good social and material status, without associated comorbidities.

- The triggering factor is the extraction of the 3.7 molar prior to the appearance of the symptoms.

- The apparently favourable evolution in the first three days of traditional treatment - incision/ drainage under local anaesthesia, wide range spectrum antibiotics treatment - comes in contrast with the imagistic result obtained during the neck CT scan with contrast substance (retropharyngeal abscess fused at the level of the posterior superior mediastinum) 
- The possibility to make a high-quality imagistic investigation was a real help in guiding the surgical exploration, since groove had to be opened and normal tissues sacrificed.

- The surgical operation requires good knowledge of the topographic anatomy of the neck, as well as experience in the management of such type of suppurations. It is important not only to discover the purulent collection, but also to apply a large drainage, while conserving as much as possible the neighbouring noble tissues (vases, nerves, intrinsic musculature of the pharynx). The golden rule is for the wound to remain non-sutured and to be cleansed and debrided daily ${ }^{10}$.

- Four days after surgery, a new control CT neck was made to determine the precision of the drainage. This did not detect recurrent collection, both at cervical level and mainly at mediastinal level.

- The condition of the patient was critical during the first seven days after surgery, both due to the severity of the cervical and mediastinal lesions and to the development of a hallucinatory psychosis. It required psychiatric therapeutic support and permanent monitoring for 10 days in the intensive care unit.

- The age of the patient and her good biological conditions ware factors facilitating the good response of the body to the therapy applied and the spectacularly fast recovery; the presence of mediastinitis being a factor increasing the mortality rate by 20-50\%.

- During her admission, the patient benefited from psychological therapy, which she continued after discharge.

- The aesthetic sequelae are considerable, the patient presenting bilateral lateral cervical keloid scars, which require future plastic surgery.

\section{Conclusions}

The diagnosis of clinical suspicion based on anamnesis and local clinical examination remains crucial, since in the incipient phases of the disease there are no obvious signs upon palpation or inspection, and the early application of the treatment is the main favourable prognostic factor. ${ }^{11}$

The CT scan of the cervical region is the most often used method for the diagnosis of the deep cervical infections. However, although CT-scan may be extremely useful in evaluation the localization and extension of the infection, the distinction between cellulitis and abscess is not always possible. ${ }^{12}$

The management of the cervical suppurations is a challenge, both from the point of view of the diagnosis and mainly from the point of view of the therapy $^{13,14}$. It has to rely on multi-disciplinary collaboration $^{15,16}$. The clinical and surgical experience of the medical team is crucial in saving these cases, with as small sequelae as possible. The surgical drainage of the collection is the standard treatment, and tracheotomy has to be carried out whenever there is a risk of obstruction or aspiration at the level of the respiratory tract ${ }^{17-19}$. Even if the incidence of the cervical suppurations decreased as a result of the large-scale use of antibiotics, they remain some of the most frequent ENT emergencies, requiring long intensive care and a high rate of hospitalization.

Cervical suppurations are also an issue from the perspective of the hospitalization costs. For the first case, the costs were $11800 €$, while for the second they were $5500 €$. The solving of these complex cases required interdisciplinary collaboration: ENT, ICU, cardiology, infectious diseases, radiology, kineto-therapy, psychiatry, psychology.

\section{Compliance with Ethics Requirements:}

„The authors declare no conflict of interest regarding this article"

"The authors declare that all the procedures and experiments of this study respect the ethical standards in the Helsinki Declaration of 1975, as revised in 2008(5), as well as the national law. Informed consent was obtained from all the patients included in the study"

"No funding for this study"

\section{Acknowledgements}

We would like to thank each member of the medical team who contributed to the case resolution and also the patients.

\section{References}

1. Atishkumar B, Vijayalaxmi A, Pallavi K. Deep neck space infection - A retrospective study of 270 cases at tertiary care center, World Journal of Otorhinolaryngology - Head and Neck Surgery 2016; 2(4): 208-213.

2. Gillespie B: Neck Spaces and Fascial Planes. In: Essential Otolaryngology, ed.: Lee KJ, Chan Y, Das S, The United States of America: McGraw-Hill Companies, Inc. 2012: $557-575$

3. Shraddha J, Kumar S, Kumar N, Puttewar M, Nagpure P. Deep-neck space infections - a diagnostic dilemma! Indian Journal of Otolaryngology and Head $\mathcal{E}$ Neck Surgery 2008; 60:349-352.

4. Adoviča A, Veidere L, Ronis M. Deep neck infections: review of 263 cases. Polish Journal of Otolaryngology 2017; 71 (5): $37-42$.

5. Barber BR, Dziegielewski PT, Biron VL, Ma A, Seikaly H. Factors associated with severe deep neck space infections: targeting multiple fronts. Journal of Otolaryngology - Head $\mathcal{E}$ Neck Surgery 2014;43(31):35 
6. Diamantis S, Giannakopoulos H, Chou J, Foote J. Descending necrotizing mediastinitis as a complication of odontogenic infection. International Journal of Surgery Case Reports 2011;2:65-67

7. Zheng L, Yang C, Kim E, Zhang W, Cai X, Jiang B. The clinical features of severe multi-space infections of the head and neck in patients with diabetes mellitus compared to non-diabetic patients. British Journal of Oral and Maxillofacial Surgery 2012; 50:757-61.

8. Kauffmann P, Cordesmeyer R, Tröltzsch M, Sömmer C, Laskawi R. Deep neck infections: A single-center analysis of 63 cases. Medicina Oral Patologia Oral y Cirugia Bucal 2017; 22(5): e536-e541.

9. Alaani A, Griffiths H, Minhas SS, Olliff J, Lee AB Parapharyngeal abscess: diagnosis, complications and management in adults. European Archives of Oto-Rhino-Laryngology 2005; $262-345$.

10. Boscolo-Rizzo P, Stellin M, Muzzi E, Mantovani M, Fuson R, Lupato V. Deep neck infections: a study of 365 cases highlighting recommendations for management and treatment. European Archives of Oto-Rhino-Laryngology 2012; 269:1241-9.

11. Marioni G, Staffieri A, Parisi S, Marchese-Ragona R, Zuccon A, Staffieri C. Rational diagnostic and therapeutic management of deep neck infections: analysis of 233 consecutive cases. Annals of Otology, Rhinology, and Laryngology 2010;119:181-7.
12. Wang B, Gao BL, Xu GP, et al. Images of deep neck space infection and the clinical significance. Acta Radiologica 2014; 55:945-951.

13. Tiglis M, Neagu TP, Elfara M, et al. Nefopam and its role in modulating acute and chronic pain. Rev Chim (Bucharest) 2018;69(10):2877-2880.

14. Diaconu C, Balaceanu A, Morosan E. Sepsis biomarkers: past, present and future. Farmacia 2015;63(6):811-815.

15. Mayor G.P., Millan J.M.S., Martinez V.A. Is conservative treatment of deep neck space infections appropriate? Head E Neck 2001; 23:126-133.

16. Tica OA, Tica O, Antal L, et al. Modern oral anticoagulant treatment in patients with atrial fibrillation and heart failure: insights from the clinical practice. Farmacia 2018;66(6):972-976.

17. Cho SY, Woo JH, Kim YJ, et al. Airway management in patients with deep neck infections - a retrospective analysis. Medicine (Baltimore) 2016 ; 95(27): e4125.

18. Stalfor J, Adielsson A, Ebenfelt A, Nethander G, Westin T. Deep neck space infections remain a surgical challenge: a study of 72 patients. Acta Oto-laryngologica 2004; 124:11911196.

19. Kang SK, Lee S, Kang MW, et al. Clinical features of deep neck infections and predisposing factors for mediastinal extension. Korean Journal of Thoracic and Cardiovascular Surgery 2012; 45(3): 171-176. 